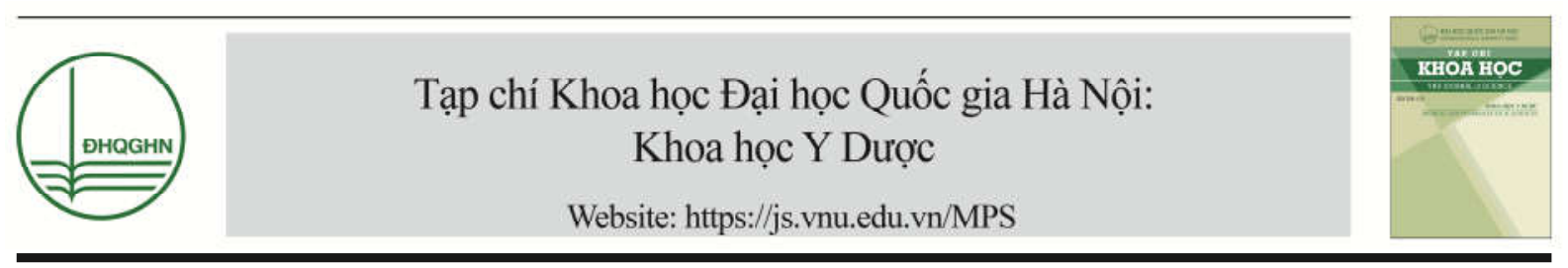

\title{
Thực trạng sử dụng thuốc trên bệnh nhân trầm cảm tại Viện Sức khỏe Tâm thần Quốc gia - Bệnh viện Bạch Mai
}

\author{
Nguyễn Thành Hải ${ }^{1, *}$, Nguyễn Hương Ly ${ }^{1}$, Nguyễn Văn Tuấn ${ }^{2}$, \\ Nguyễn Xuân Bách ${ }^{3}$ \\ ${ }^{I}$ Đại học Dược Hà Nội, 13-15 Lê Thánh Tông, Hoàn Kiếm, Hà Nội, Việt Nam \\ ${ }^{2}$ Viện Sức khỏe Tâm thần-Bệnh viện Bạch Mai, 78 Giải Phóng, Đống Đa, Hà Nội, Việt Nam \\ ${ }^{3}$ Khoa Y Duoọc, Đại học Quốc gia Hà Nội, 144 Xuân Thủy, Cầu Giấy, Hà Nội, Việt Nam \\ Nhận ngày 03 tháng 7 năm 2017 \\ Chỉnh sửa ngày 23 tháng 10 năm 2017; Chấp nhận đăng ngày 12 tháng 6 năm 2018
}

\begin{abstract}
Tóm tắt: Rối loạn trầm cảm là một trong các bệnh lý gây ra gánh nặng bệnh tật cho bệnh nhân. Việc sử dụng thuốc trong điều trị trầm cảm vẫn chưa có hướng dẫn điều trị chuẩn tại Việt $\mathrm{Nam}$. Phương pháp nghiên cứu: Nghiên cứu thuần tập trên 65 bệnh nhân trầm cảm tại Viên Sức khỏe Tâm thần Quốc gia - Bệnh viện Bạch Mai nhằm đánh đưa ra thực trạng sử dụng thuốc, biến cố bất lợi và hiệu quả điều trị. Kết quả: cho thấy sertralin là thuốc được sử dụng nhiều nhất (39.5\%), tiếp đến là mirtazapin $(38,3 \%)$. Biến cố bất lợi trên triệu chứng hay gặp nhất là trên cholinergic. Có 12 bệnh nhân $(18,5 \%)$ được ghi nhận gặp biến cố bất lợi trên cân nặng. Tỉ lệ thuyên giảm điểm theo thang HAM-D 17 sau quá trình điều trị là $66,2 \pm 13,8 \%$. Kết luận: Các thuốc chống trần cảm mới được sử dụng nhiều và có hiệu quả trên các bệnh nhân trầm cảm ở Việt Nam. Bác sĩ lâm sàng cần chú ý đến biển cố bất lợi của thuốc như tác dụng trên cholinergic và trên cân nặng.
\end{abstract}

Từ khóa: Thuốc chống trầm cảm, trầm cảm, tác dụng phụ, sử dụng thuốc.

\section{1. Đặt vấn đề}

Trầm cảm là một trong những rối loạn tâm thần phổ biến, ảnh hưởng tới người bệnh, gia đình và xã hội. Điều trị trầm cảm đòi hỏi tốn rất nhiều thời gian, kết hợp sử dụng các liệu pháp khác nhau. Trong đó liệu pháp hóa dược vẫn được coi là liệu pháp điều trị thường dùng nhất [1]. Trên thực tế lâm sàng, các thuốc chống trầm cảm với nhiều cơ chế cho hiệu quả cao trong điều trị nhưng cũng có nhiều tác dụng phụ và tương tác thuốc có thể xảy ra trong quá trình sử dụng [2]. Viện Sức khỏe Tâm thần - Bệnh viện Bạch Mai là cơ sở hàng đầu trong điều trị các bệnh lý rối loạn tâm thần, trong đó có bệnh lý trầm cảm. Nghiên cứu này được thực hiện nhằm đưa ra thực trạng về tình hình sử dụng thuốc trên bệnh nhân trầm cảm tại Viện Sức khỏe Tâm thần - Bệnh viện Bạch Mai.

\footnotetext{
*Tác giả liên hệ. ĐT.: 84-901986688.

Email: haithanh4780@yahoo.com

https://doi.org/10.25073/2588-1132/vnumps.4075
} 


\section{2. Đối tượng và phương pháp nghiên cứu}

\section{1. Đối tượng nghiên cưu}

Các bệnh án của bệnh nhân đang được điều trị nội trú tại Viện Sức khỏe Tâm thần - Bệnh viện Bạch Mai, từ 02-07/2016.

Tiêu chuẩn lựa chọn:

Tất cả các bệnh án của bệnh nhân được chẩn đoán rối loạn trầm cảm (Mã bệnh án F32 và $\mathrm{F} 33$ theo $\mathrm{ICD}-10$ ) có sử dụng it nhất một thuốc chống trầm cảm.

Tiêu chuẩn loại trù:

Bệnh nhân chuyển khoa khác trong quá trình điều trị

Bệnh nhân không tuân thủ điều trị

\subsection{Phuơng pháp nghiên cứu}

Nghiên cứu tiến cứu theo dõi dọc, không can thiệp, thu thập kết quả dựa trên phiếu khảo sát.

\subsection{Xử lý kết quả}

Phân tích các giá trị thu được bằng phần mềm thống kê y học SPSS 20.0. Giá trị khác nhau có ý nghĩa thống kê nếu p $<0,05$.

Bảng 1. Đặc điểm chung của nhóm bệnh nhân nghiên cứu $(\mathrm{n}=65)$

\begin{tabular}{llll}
\hline Tiêu chí đánh giá & & $\begin{array}{l}\text { Số } \\
\text { bệnh } \\
\text { nhân }\end{array}$ & Tỉ lệ \% \\
\hline Giới tính & Nam & 25 & 38,5 \\
& Nữ & 40 & 61,5 \\
\hline Tuổi & $<16$ & 1 & $42,0 \pm 16,5$ \\
& $16-45$ & 32 & 49,2 \\
& $45-65$ & 24 & 36,9 \\
& $>65$ & 8 & 12,3 \\
\hline $\begin{array}{l}\text { Các thể lâm sàng } \\
\text { và mức độ }\end{array}$ & Mã sồ & & \\
$\begin{array}{l}\text { Giai đoạn trầm } \\
\text { cảm }\end{array}$ & & & \\
$\begin{array}{l}\text { Vừa không có } \\
\text { triệu chứng cơ thể }\end{array}$ & F32.10 & 3 & 4,6 \\
$\begin{array}{l}\text { Vứa có triệu } \\
\text { chứng cơ thể }\end{array}$ & F32.11 & 20 & 30,8 \\
$\begin{array}{l}\text { Nặng không có } \\
\text { loạn thần }\end{array}$ & F32.2 & 6 & 9,2 \\
\hline
\end{tabular}

\begin{tabular}{llll}
\hline $\begin{array}{l}\text { Nặng có loạn thần } \\
\text { Tồng }\end{array}$ & $\mathrm{F} 32.3$ & 5 & $\begin{array}{l}7,7 \\
52,3\end{array}$ \\
$\begin{array}{l}\text { Rối loạn trầm cảm } \\
\text { tái diền }\end{array}$ & & 34 & \\
$\begin{array}{l}\text { Vừa không có } \\
\text { triệu chứng cơ thể }\end{array}$ & $\mathrm{F} 33.10$ & 3 & 4,6 \\
$\begin{array}{l}\text { Vừa có triệu } \\
\text { chứng cơ thể }\end{array}$ & $\mathrm{F} 33.11$ & 19 & 29,2 \\
$\begin{array}{l}\text { Nặng không có } \\
\text { loạn thần }\end{array}$ & $\mathrm{F} 33.2$ & 2 & 3,1 \\
Nặng có loạn thần & $\mathrm{F} 33.3$ & 7 & 10,8 \\
\hline Tồng & & 31 & 47,7 \\
\hline
\end{tabular}

\section{Kết quả nghiên cứu}

\section{1. Đặc điểm chung của mẫu nghiên cúu}

Tỷ lệ bệnh nhân $(\mathrm{BN})$ nữ/nam là 40/25 = 1,6/1. Tuổi trung bình $42,0 \pm 16,5$ tuổi, trong đó độ tuổi từ $16-45$ chiếm tỉ lệ cao nhất $(49,2 \%)$. Mẫu nghiên cứu có $34 \mathrm{BN}$ (chiếm 52,3\%) ở giai đoạn trầm cảm và $31 \mathrm{BN}$ (chiếm $47,7 \%$ ) rối loạn trầm cảm tái diễn. Không có $\mathrm{BN}$ nào trong nhóm nghiên cứu mắc trầm cảm nhẹ. Số $\mathrm{BN}$ trầm cảm vừa có triệu chứng cơ thể chiếm tỉ lệ cao nhất, ở giai đoạn trầm cảm là $30,8 \%$ và trầm cảm tái diễn là $29,2 \%$. Tỉ lệ $\mathrm{BN}$ mắc trầm cảm nặng chiếm $16,9 \%$ (trong đó nặng không loạn thần là $9,2 \%$, nặng có loạn thần là $7,7 \%$ ). Với trầm cảm tái diễn, số $\mathrm{BN}$ mắc trầm cảm nặng là 13,9\% (trong đó nặng không loạn thần là $3,1 \%$ và nặng có loạn thần là $10,8 \%$ ).

\subsection{Khảo sát thực trạng sủ dụng thuốc chống trầm cảm}

Các nhóm thuốc chống trầm cảm được sủe dụng trong điều trị rối loạn trầm cảm

Trong các thuốc được sử dụng trên $\mathrm{BN}$ nghiên cứu, nhóm SSRI được sử dụng nhiều nhất, điển hình là sertralin chiếm tỉ lệ 39,5\%. Thuốc hay được sử dụng tiếp theo là mirtazapin, chiếm 38,3\%. Nhóm TCA được sử dụng ít nhất 18,5\%. 
Bảng 2. Các thuốc chống trầm cảm sử dụng trong điều trị

\begin{tabular}{lllll}
\hline Nhóm & Tên thuốc & Hàm lượng & Số lượt dùng & Tỉ lệ \% \\
\hline TCA & Amitriptylin & $25 \mathrm{mg}$ & 15 & 18,5 \\
& Sertralin & $50 \mathrm{mg}$ & 32 & 39,5 \\
SSRI & Paroxetin & $20 \mathrm{mg}$ & 1 & 1,2 \\
& Fluvoxamin & $100 \mathrm{mg}$ & 2 & 2,5 \\
Đối kháng 02 - & Mirtazapin & $30 \mathrm{mg}$ & 31 & 38,3 \\
adrenergic & & & 81 & 100 \\
\hline Tổng & & &
\end{tabular}

TCA: Thuốc chống trầm cảm ba vòng; SSRI: Nhóm thuốc ức chế thu hồi serotonin

Các thuốc hỗ trợ điều trị triệu chứng tâm thần trên bệnh nhân trầm cảm.

Tỉ lệ BN sử dụng kết hợp thêm thuốc an thần diazepam chiếm cao nhất $(67,7 \%)$. Trong nhóm thuốc an thần kinh, olanzapin được sử dụng kết hợp nhiều nhất $(44,6 \%)$, tiếp đến là sulpirid $(18,5 \%)$, haloperidol $(15,4 \%)$. Chỉ có 3 $\mathrm{BN}$ sử dụng kết hợp thuốc chỉnh khí sắc $(4,6 \%)$.

Bảng 3. Các thuốc hỗ trợ điều trị triệu chứng tâm thần trên bệnh nhân trầm cảm

\begin{tabular}{llll}
\hline Nhóm thuốc & Hoạt chất & $\begin{array}{l}\text { Số } \\
\text { BN }\end{array}$ & $\begin{array}{l}\text { Tỉ lệ } \\
\%\end{array}$ \\
\hline \multirow{4}{*}{ An thần kinh } & Olanzapin & 29 & 44,6 \\
(ATK) & Risperidon & 5 & 7,7 \\
& Quetiapin & 6 & 9,2 \\
An thần & Haloperidol & 10 & 15,4 \\
Chỉnh khí sắc & Sulpirid & 12 & 18,5 \\
& Diazepam & 44 & 67,7 \\
\hline
\end{tabular}

Phác đồ điều trị trầm cảm sủ dụng trên bệnh nhân rối loạn trầm cảm

Phác đồ được lựa chọn nhiều nhất là thuốc chống trầm cảm và an thần kinh $(\mathrm{CTC}+\mathrm{ATK})$, với tî̉ lệ sử dụng tại thời điểm ban đầu chiếm và sau quá trình thay đổi thuốc là $66,1 \%$ và $67,7 \%$.

Bảng 4. Phác đồ điều trị được sử dụng trên bệnh nhân trầm cảm

\begin{tabular}{lll}
\hline \multirow{2}{*}{ Phác đồ } & \multicolumn{2}{l}{ Số bệnh nhân (Tỉ lệ \%) } \\
\cline { 2 - 3 } & Ban đầu & Thay thế \\
\hline CTC & $20(30,8)$ & $13(20,0 \%)$ \\
CTC + ATK & $43(66,1)$ & $44(67,7 \%)$ \\
CTC + CTC & $2(3,1)$ & $5(7,7 \%)$ \\
CTC + CTC + ATK & $0(0)$ & $3(4,6 \%)$ \\
\hline Tổng & $65(100 \%)$ & $65(100 \%)$ \\
\hline
\end{tabular}

Các liệu pháp điều trị phối hợp trên bệnh nhân rối loạn trầm cảm.

Trong 65 bệnh nhân nghiên cứu, liệu pháp tâm lý được sử dụng trên 42 bệnh nhân (chiếm 64,62\%), có 13 bệnh nhân sử dụng TMS (chiếm $21,54 \%$ ) và 9 bệnh nhân sử dụng phối hợp cả liệu pháp tâm lý và TMS (chiếm 13,85\%).

Bảng 5. Các liệu pháp điều trị được sử dụng phối hợp liệu pháp hóa dược

\begin{tabular}{|c|c|c|}
\hline $\begin{array}{l}\text { Các liệu pháp điều trị } \\
\text { được sử dụng }\end{array}$ & $\begin{array}{l}\text { Số bệnh } \\
\text { nhân }\end{array}$ & $\begin{array}{l}\text { Tỉ lệ } \\
(\%)\end{array}$ \\
\hline Liệu pháp tâm lý & 42 & 64,61 \\
\hline $\begin{array}{l}\text { Liệu pháp kích thích từ } \\
\text { xuyên sọ (TMS) }\end{array}$ & 14 & 21,54 \\
\hline Liệu pháp tâm lý + TMS & 9 & 13,85 \\
\hline Tồng & 65 & 100 \\
\hline
\end{tabular}

3.3. Các biến cố bất lợi (ADE) ghi nhận trong quá trình sử dụng thuốc

Ghi nhận ADE trên triệu chứng của nhóm bệnh nhân nghiên cưu.

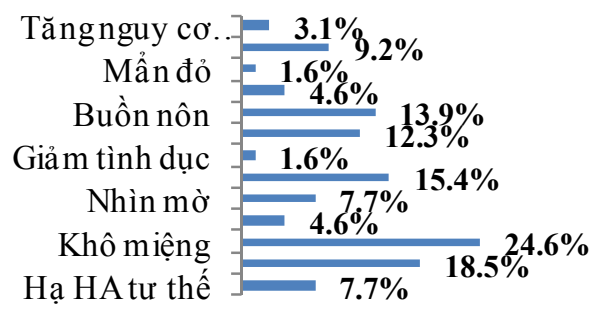

Hình 1. Tỉ lệ ADE trên triệu chứng của nhóm bệnh nhân nghiên cứu.

Biến cố hay gặp nhất trên toàn bộ nhóm BN nghiên cứu là trên cholinergic: khô miệng $(24,6 \%)$, táo bón $(18,5 \%)$. Tiếp đến hay gặp các biến cố trên thần kinh: đau đầu $(15,4 \%)$, bồn 
chồn (12,3\%). Có $1 \mathrm{BN}(1,6 \%)$ bị mẩn đỏ và 1 BN $(1,6 \%)$ gặp biến cố bất lợi gây suy giảm chức năng tình dục. Các biến cố chủ yếu ở mức độ nhẹ, không có biến cố nào ở mức độ nặng.

Ghi nhận sư thay đổi cân nặng trên nhóm bệnh nhân nghiên cưu.
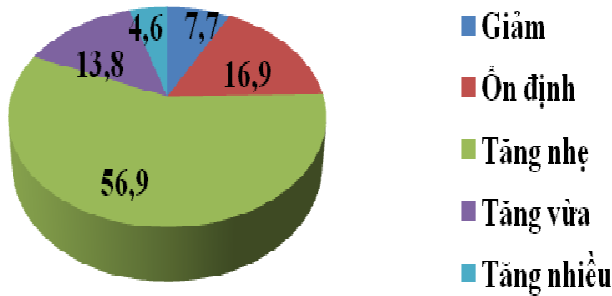

Hình 2. Tỉ lệ thay đổi cân nặng của BN.
Chín bệnh nhân theo dõi có trọng lượng cơ thể tăng vừa (chiếm $13,8 \%$ ) và $3 \mathrm{BN}$ có trọng lượng cơ thể tăng nhiều (chiếm 4,6\%). Tổng cộng có $12 \mathrm{BN}$ có mức tăng trọng lượng cơ thể $>7 \%$ (chiếm 18,46\%).

3.4. Hiệu quả điều trị thông qua mức độ thuyên giảm điểm HAM-D17

Tổng điểm HAM-D 17 trên bệnh nhân nghiên cúu tại các thời điểm đánh giá

Mức thuyên giảm điểm của cả đợt điều trị là 11,5 $\pm 3,9$. Mức điểm HAM-D 17 có sự khác nhau giữa các thời điểm đánh giá với $\mathrm{p} 0 / 1$, $\mathrm{p} 1 / 2, \mathrm{p} 2 / 3$ đều $<0,01$. Điều đó cho thấy, toàn bộ các triệu chứng của rối loạn trầm cảm có sự cải thiện rõ rệt ngay sau 1 tuần điều trị, sau 2 tuần và trước khi ra viện (Bảng 6).

Bảng 6. Tổng điểm HAM-D 17 trên bệnh nhân nghiên cứu theo các tuần điều trị

\begin{tabular}{|c|c|c|c|c|c|}
\hline & $\begin{array}{l}\text { T0 } \\
(\mathrm{n}=65)\end{array}$ & $\begin{array}{l}\text { T1 } \\
(\mathrm{n}=65)\end{array}$ & $\begin{array}{l}\text { T2 } \\
(n=62)\end{array}$ & $\begin{array}{l}\text { T3 } \\
(\mathrm{n}=58)\end{array}$ & $\mathrm{P}$ \\
\hline $\begin{array}{l}\text { Điểm HAM-D } 17 \\
(\bar{x} \pm \mathrm{SD})\end{array}$ & $17,3 \pm 4,2$ & $12,4 \pm 3,6$ & $8,7 \pm 2,9$ & $5,8 \pm 2,5$ & $\begin{array}{l}\mathrm{p} 0 / 1=0,0001 \\
\mathrm{p} 1 / 2=0,0001\end{array}$ \\
\hline $\begin{array}{l}\text { Điểm thuyên } \\
\operatorname{giảm}(\bar{x} \pm \mathrm{SD})\end{array}$ & & $4,9 \pm 2,3$ & $3,8 \pm 2,2$ & $2,9 \pm 1,3$ & $\mathrm{p} 2 / 3=0,0001$ \\
\hline
\end{tabular}

Tỉ lệ thuyên giảm các triệu chưng qua mức độ thuyên giảm điểm HAM-D 17.

Tỉ lệ thuyên giảm các triệu chứng lâm sàng chung và các nhóm triệu chứng chính có sự khác nhau giữa các thời điểm đánh giá với p1/2, $\mathrm{p} 2 / 3<0,01$. Điều này cho thấy các triệu chứng lâm sàng đều được cải thiện qua các thời điểm đánh giá.

Bảng 7. Tỉ lệ thuyên giảm các triệu chứng lâm sàng theo thang HAM-D 17

\begin{tabular}{|c|c|c|c|c|}
\hline \multirow{2}{*}{ Nhóm triệu chứng } & \multicolumn{3}{|c|}{ Tỉ lệ thuyên giảm $(\%)(\bar{x} \pm \mathrm{SD})$} & \multirow[b]{2}{*}{$\mathrm{p}$} \\
\hline & Sau 1 tuần $(\mathrm{n}=65)$ & Sau 2 tuần $(\mathrm{n}=62)$ & Trước ra viện $(\mathrm{n}=58)$ & \\
\hline $\begin{array}{l}\text { Triệu chứng } \\
\text { chung }\end{array}$ & $28,2 \pm 11,6$ & $49,6 \pm 14,6$ & $66,2 \pm 13,8$ & $\begin{array}{l}\mathrm{p} 1 / 2=0,0001 \\
\mathrm{p} 2 / 3=0,0001\end{array}$ \\
\hline Khí sắc & $31,7 \pm 20,9$ & $52,3 \pm 20,7$ & $69,0 \pm 19,6$ & $\begin{array}{l}\mathrm{p} 1 / 2=0,0001 \\
\mathrm{p} 2 / 3=0,0001\end{array}$ \\
\hline Giấc ngủ & $40,4 \pm 27,1$ & $76,7 \pm 31,9$ & $83,1 \pm 18,5$ & $\begin{array}{l}\mathrm{p} 1 / 2=0,0001 \\
\mathrm{p} 2 / 3=0,0001\end{array}$ \\
\hline Vận động & $26,5 \pm 15,3$ & $42,9 \pm 30,2$ & $65,1 \pm 23,3$ & $\begin{array}{l}\mathrm{p} 1 / 2=0,0001 \\
\mathrm{p} 2 / 3=0,0001\end{array}$ \\
\hline Lo âu & $19,3 \pm 17,0$ & $31,3 \pm 25,6$ & $46,0 \pm 27,4$ & $\begin{array}{l}\mathrm{p} 1 / 2=0,0001 \\
\mathrm{p} 2 / 3=0,0001\end{array}$ \\
\hline $\begin{array}{l}\text { Rối loạn cơ thể và } \\
\text { nhận thức }\end{array}$ & $24,1 \pm 17,4$ & $44,9 \pm 20,3$ & $61,8 \pm 19,3$ & $\begin{array}{l}\mathrm{p} 1 / 2=0,0001 \\
\mathrm{p} 2 / 3=0,0001\end{array}$ \\
\hline
\end{tabular}




\section{Bàn luận}

Trong nghiên cứu của chúng tôi cho thấy tỉ lệ các thuốc SSRI (sertralin, paroxetin) được sử dụng nhiều nhất, tiếp đến là mirtazapin, thấp nhất là chống trầm cảm ba vòng. Theo hướng dẫn điều trị của hội tâm thần Hoa Kỳ [[1]], với hầu hết bệnh nhân $(\mathrm{BN})$, lựa chọn tối ưu ban đầu là SSRI, mirtazapin hoặc bupropion. Như vậy việc lựa chọn sử dụng thuốc chống trầm cảm tại Viện Sức khỏe Tâm thần là phù hợp với xu thế chung trên thế giới.

Phác đồ được sử dụng nhiều nhất là kết hợp chống trầm cảm và an thần kinh (CTC + ATK) (chiếm $66,1 \%$ ). Liệu pháp kết hợp chống trầm cảm và an thần kinh cũng là liệu pháp hay được sử dụng trên lâm sàng hiện nay, vừa tăng hiệu quả điều trị trên bệnh nhân, vừa hạn chế tác dung phụ do sử dụng thuốc chống trầm cảm liều cao và một số thuốc chống loạn thần như Risperidon, Quetiapin, Olanzapin đã được chứng minh có hiệu quả trong điều trị trầm cảm [3]. Tỉ lệ $\mathrm{BN}$ sử dụng kết hợp thêm thuốc an thần diazepam chiếm $67,7 \%$ do đa số $\mathrm{BN}$ khi nhập viện có triệu chứng bồn chồn, mất ngủ dai dẳng, mệt mỏi. Các biến cố bất lợi ghi nhận được chủ yếu trên hệ cholinergic, tuy nhiên chưa thể kết luận được chính xác thuốc gây ra các biến cố bất lợi trên. Có $12 \mathrm{BN}$ có mức tăng cân $>7 \%$ (chiếm 18,5\%). Như vậy việc tăng trọng lượng cơ thể có thể coi là một biến cố bất lợi có thể gặp trên $\mathrm{BN}$. Điều này đặc biệt lưu ý với $\mathrm{BN}$ thừa cân do có thể dẫn đến các bệnh lý liên quan khác do béo phì như tiểu đường, tim mạch, tăng huyết áp [4].

Về hiệu quả điều trị: tỉ lệ thuyên giảm theo thang HAM-D 17 trên nhóm BN nghiên cứu sau điều trị là $66,2 \pm 13,8 \%$. Mức điểm HAM-D 17 có sự khác nhau giữa các thời điểm đánh giá với $\mathrm{p} 0 / 1, \mathrm{p} 1 / 2, \mathrm{p} 2 / 3$ đều $<0,01$. Tỉ lệ thuyên giảm các nhóm triệu chứng chính cũng có sự khác biệt có ý nghĩa thống kê với p1/2, p2/3< 0,01 . Như vậy trên toàn bộ $\mathrm{BN}$, tỉ lệ thuyên giảm bệnh thể hiện ngay sau tuần đầu tiên điều trị và tăng dần ở các tuần tiếp theo trong quá trình điều trị. Điều này phản ánh hiệu quả và mức độ đáp ứng thực tế trong điều trị trên lâm sàng.

\section{Kết luận}

Sertralin là thuốc chống trầm cảm được sử dụng nhiều nhất $(39,5 \%)$, tiếp đến là mirtazapin $(38,3 \%)$. Phác đồ được sử dụng nhiều nhất là kết hợp thuốc chống trầm cảm và an thần kinh $(66,1 \%)$. Biến cố bất lợi trên triệu chứng hay gặp nhât là trên cholinergic. Có 12 bệnh nhân $(18,5 \%)$ được ghi nhận gặp biến cố bất lợi trên cân nặng. Điểm HAM-D 17 có sự thuyên giảm có ý nghĩa thống kê tại các thời điểm đánh giá. Tỉ lệ thuyên giảm điểm theo thang HAM-D 17 sau quá trình điều trị là $66,2 \pm 13,8 \%$.

\section{Tài liệu tham khảo}

[1] American Psychiatric Association, Practice guiline for the treatment of patients with major depressive disorder, Third Edition (2010).

[2] Duval, Lebowitz, Macher, "Treatments in Depression", Dialogues in Clinical Neuroscience, 8 (2006) 191.

[3] Raj Rasasingham, "Efficacy and Safety of Antipsychotics for the Treatment of Major Depressive Disorder in Adolescents and Adults: Current Issues and Clinical Perspective", Open Journal of Psychiatry, 4 (2014) 182.

[4] Kessler RC, McGonagle KA, Swartz M, Blazer DG, Nelson CB. "Sex and depression in the National Comorbidity Survey I: Lifetime prevalence, chronicity and recurrence", Journal of Affectice Disorders, 29 (1993) 85. 


\title{
The Use of Antidepressants in Depressed Patients in the National Institute of Mental Health - Bach Mai Hospital
}

\author{
Nguyen Thanh $\mathrm{Hai}^{1}$, Nguyen Huong Ly ${ }^{1}$, Nguyen Van Tuan ${ }^{2}$, Nguyen Xuan Bach \\ ${ }^{1}$ Hanoi University of Pharmacy, 13-15 Le Thanh Tong, Hoan Kiem, Hanoi, Vietnam \\ ${ }^{2}$ National Institute of Mental Health, Bach Mai Hospital, 78 Giai Phong, Dong Da, Hanoi, Vietnam \\ ${ }^{3}$ VNU School of Medicine and Pharmacy, 144 Xuan Thuy, Cau Giay, Hanoi, Vietnam
}

\begin{abstract}
According to the WHO (World Health Organization), unipolar depressive disorders were ranked as the third leading cause of the Global Burden of Disease in 2004 and are expected to move into the first place by 2030. Methods: Research conducted on 65 patients at the National Institute of Mental Health to examine the use of drugs, their side effects, drug interactions and effectiveness of treatment in these patients. Results: The study results showed that Sertraline was the most widely used antidepressant (39.5\%), followed by Mirtazapine (38.3\%). Adverse events in the most common symptoms were resulted from cholinergics. There were 12 patients $(18.5 \%)$ recorded experiencing adverse events on weight. The rate of remission HAM-D 17 scale scores after treatment was $66.2 \pm 13.8 \%$. Conclusions: New antidepressants were commonly used and had effects among the unipolar depressive patients in Vietnam. Clinicians should pay attention to such side effects as cholinergic adverse events and weight gain among patients.
\end{abstract}

Keywords: Antidepressant, depression, side effects, drug use. 